\title{
Editorial
}

Annals of
Neurosclences

\section{Educational Neuroscience: Challenges and Opportunities}

\author{
P.N. Tandon Nandini Chatterjee Singh
}

National Brain Research Centre, Gurgaon, India

Educational neuroscience is an emerging multidisciplinary field wherein the aim is to link basic research in neuroscience, psychology and cognitive science, with educational technology. Broadly speaking, it explores the relationship between education and 'Brain Sciences', the latter encompassing neurosciences, child psychology and cognitive science. Batro in 2011 pointed out that 'the bridges between brain sciences and education are numerous and quickly developing. Neuroplasticity is the key bridging process and its molecular, neuronal and brainwide mechanisms should be better investigated in future'. Additionally, 'the methods of brain and cognitive sciences have reached a stage where we can now objectively monitor the developmental trajectory of the child's brain and document how this trajectory is being shaped by parenting, education and other environmental influences'. Dehaene [1] claimed that 'human cognitive neuroscience has made enormous strides in understanding the specific cerebral circuits underlying particular domain of education, such as mathematics, reading and language acquisition'. Conversely, there are those like Bruer, a cognitive scientist and a philosopher of science, who object to the term 'Educational Neuroscience' and wish to consider child psychology, neuroscience and cognitive science as distinct disciplines. Nevertheless, even he acknowledged that 'educational applications of brain sciences may come

\section{KARGER}

(c) 2016 S. Karger AG, Basel

0972-7531/16/0232-0063\$39.50/0

E-Mail karger@karger.com

www.karger.com/aon eventually, but as of now neuroscience has little to offer teachers in terms of informing classroom practice. There is, however, a science of mind, cognitive science that can serve as a basic science for the development of an applied science of learning and instruction'. Abundant information has accumulated in the last 2 decades as a result of coming together of various disciplines, which directly or indirectly are dependent on the understanding of brain structure and function. This approach is akin to that of Andrew N. Meltzoff and Patricia K. Kuhl, co-directors of the Institute of Learning and Brain Science, Washington. They proposed that neuroscientists are beginning to understand the brain mechanisms underlying learning. It is generally agreed that new insights from many fields are converging to create a new science of learning that may transform educational practices [2, 3]. Correspondingly, Albert Galaburda, Professor of Neurology and Neuroscience, Harvard Medical School, Boston, stated, 'Knowledge from neuroscience also lends itself to applications to education and I would hypothesize that the predictive value of neuroscience data to learning is opt to be greater than that of genetic data' [4].

There are 2 main streams of knowledge which link neuroscience to education: (i) brain structures responsible for various educational processes like reading, attention, memory, calculation, language acquisition, etc. and 
(ii) the manner in which educational processes affect brain structure and function. Extensive research over the last few years has demonstrated the role of these processes in learning, more specifically in the field of literacy and education. For instance, learning to read is also one of the most elegant examples of the neuroplasticity of the brain. According to the neuronal recycling hypothesis [5], in order to learn to read, children need to learn to associate sounds with letters, forming neural circuits between brain structures, originally specialized for seeing (the occipital cortex) and for hearing (the auditory cortex) [5]. Functional neuroimaging, which allows brain activity to be recorded while performing a task, provides a unique opportunity to understand and visualize the neural circuits that are formed during the period reading is acquired and mastered. Despite conventional instruction, adequate intelligence and sociocultural opportunity, a few children fail to achieve age-appropriate reading skills. This is defined as developmental dyslexia and is known to occur due to structural or functional disruption of the reading network in the brain. The incidence of dyslexia worldwide has been reported to be around $15-17 \%$ and is a matter of great educational concern [6]. However, if detected early, children with dyslexia can be provided systematic personalized instruction that can help them cope with reading but this must be done as early as possible. Neurocognitive theories of dyslexia have been developed [7] that make the presumption that all dyslexics have the same type of brain abnormality irrespective of the properties of the orthographic system used to write their language. However, the neural circuits involved in reading and reading disorders are expected to vary substantially across languages, because of differences in how a given writing system links printed to spoken language [8-14]. Besides, it is known and widely accepted that even within a single orthographic community there are different subtypes of dyslexia [15-18].

There is a growing concern globally and especially in India that our school education system needs radical changes to meet the challenges of the 21 st century. For instance, wherein the state education system has a 3-language formula, children are often required to learn to read as many as 3 distinct languages by the age of 10 . The situation can be daunting for the child and the parent, particularly in situations when parents themselves are unable to read the language and thereby are inept at helping the child at home. Therefore, first of all, it is critical that school instructions be adequate and paced at the appropriate level for the child. Reading builds on spoken language skills and it is critical to ascertain whether the child is exposed to 2 or more language environments at home or a single language. This is important because children may be imparted instruction in a language that they do not speak in the home environment. In addition, writing systems vary in script and orthography. Orthography is sound-letter mapping and describes the correspondence between script and sound. Orthographies that have simple one-to-one sound-letter mapping are termed transparent whereas those in which sound-letter mapping is complex are classified as deep. Since learning to read requires children to understand the rules of the writing system, if languages belong to the same writing systems there can be a transfer of literacy skills across languages whereas if writing systems differ the child has the additional challenge of learning the rules of both.

Furthermore, it is now well established that approximately $10 \%$ children undergo learning difficulties due to developmental disorders - dyslexia, dyscalculia, autism syndrome, hyperkinetic attention disorders, etc., which require special educational strategies. Cognitive impairment among the socioeconomically underprivileged children who have problems adjusting to the educational environment directed to children from the more privileged strata of society can be added to this data as well. To be able to attend to the educational needs of these diverse groups of children it would first be necessary to identify these groups scientifically and then to adjust our teaching knowledge from brain research. However, for successful implementation of any such programme, it is necessary that the teachers, pedagogists, child psychologists and cognitive neuroscientists should come together. The scientists at National Brain Research Centre in consort with like-minded researchers from different parts of the country have initiated work in this direction under the aegis of the Cognitive Science Programme of DST. To provide an impetus for such collaboration and its wider dissemination, we propose to bring this activity under the umbrella of 'Educational Neuroscience'.

References

1 Dehaene S: The Massive Impact of Literacy on the Brain and Its Consequences for Education. Human Neuroplasticity and Education, Pontifical Academy of Sciences, 2011, pp 1932.

2 Kuhl PK: Early language learning and literacy: neuroscience implications for education. Mind Brain Educ 2011;5:128-142.

3 Cheryan S, Meltzoff AN, Kim S: Classrooms matter: the design of virtual classrooms influences gender disparities in computer science classes. Computers Educ 2011;57:1825-1835.
Ann Neurosci 2016;23:63-65 DOI: $10.1159 / 000443560$
Tandon/Singh 
4 Galaburda AM: Neuroscience, education, and learning disabilities; in Battro AM, Dehaene S, Singer WJ (eds): Human Neuroplasticity and Education, 2010, p 151.

5 Dehaene S, Cohen L: Cultural recycling of cortical maps. Neuron 2007;56:384-398.

6 Snowling MJ: Dyslexia. Blackwell Publishing, 2000.

7 Silani G, Frith U, Demonet JF, et al: Brain abnormalities underlying altered activation in dyslexia: a voxel based morphometry study. Brain 2005;128(pt 10):2453-2461.

8 Tan LH, Spinks JA, Eden GF, et al: Reading depends on writing, in Chinese. Proc Natl Acad Sci U S A 2005;102:8781-8785.

9 Goswami U: Phonology, reading development, and dyslexia: a cross-linguistic perspective. Ann Dyslexia 2002;52:139-163.
10 Ziegler JC, Goswami U: Becoming literate in different languages: similar problems, different solutions. Dev Sci 2006;9:429-436.

11 Bolger DJ, Perfetti CA, Schneider W: Crosscultural effect on the brain revisited: universal structures plus writing system variation. Hum Brain Mapp 2005;25:92-104.

12 Price CJ, Mechelli A: Reading and reading disturbance. Curr Opin Neurobiol 2005;15: 231-238.

13 Schlaggar BL, McCandliss BD: Development of neural systems for reading. Annu Rev Neurosci 2007;30:475-503.

14 Siok WT, Perfetti CA, Jin Z, et al: Biological abnormality of impaired reading is constrained by culture. Nature 2004;431:71-76.
15 Coltheart M, Curtis B, Atkins P: Models of reading aloud: dual-route and parallel-distributed-processing approaches. Psychol Rev 1993;100:589-608.

16 Heim S, Tschierse J, Amunts K, et al: Cognitive subtypes of dyslexia. Acta Neurobiol Exp (Wars) 2008;68:73-82.

17 King WM, Giess SA, Lombardino LJ: Subtyping of children with developmental dyslexia via bootstrap aggregated clustering and the gap statistic: comparison with the double-deficit hypothesis. Int J Lang Commun Disord 2007;42:77-95.

18 Lorusso ML, Facoetti A, Pesenti S, et al: Wider recognition in peripheral vision common to different subtypes of dyslexia. Vision Res 2004;44:2413-2424. 